\title{
The social behaviour in zebrafish (Danio rerio) - the metabolic, neuropsychiatric and ecotoxicological relevance
}

\author{
Viorica Rarinca, Gabriel Plăvan, Ştefan-Adrian Strungaru, \\ Alin Ciobîcă, Daniel Timofte, Mircea Nicoară
}

\begin{abstract}
Viorica Rarinca - Alexandru Ioan Cuza University of Iasi, Faculty of Biology, Iasi, Romania
Gabriel Plăvan - Alexandru Ioan Cuza University of Iasi, Department of Biology, Faculty of Biology, Iasi, Romania

Ştefan-Adrian Strungaru - Alexandru Ioan Cuza University of Iasi, Department of Research, Faculty of Biology, Iasi, Romania

Alin Ciobîcă - PhD, researcher, Alexandru Ioan Cuza University of Iasi, Department of Research, Faculty of Biology, Bd. Carol I, 20A, 700505, Iasi, Romania, Academy of Romanian Scientists, Splaiul Independentei nr. 54, sector 5, 050094 Bucuresti, Romania, Center of Biomedical Research, Romanian Academy, Iasi, B-dul Carol I, no 8, Romania

Daniel Timofte - MD, PhD, professor, "Grigore T.Popa” University of Medicine and Pharmacy, Iasi, Romania
\end{abstract}

Mircea Nicoară - Alexandru Ioan Cuza University of Iasi, Department of Biology, Faculty of Biology, Iasi, Romania

\begin{abstract}
Zebrafish (Danio rerio), a teleost cyprinid, is a species that became an ideal model for aquatic ecotoxicology due to large spectrum of methodologies developed in early 1980. Zebrafish as a model organism has many advantages, such as: reduced costs (fish breeding is cheaper than mice), small size, ex utero development of the embryo and individuals grow at a rapid rate (mature adults develop in about three months) and embryos are transparent. In addition, zebrafish has a high degree of homology to the human genome, which is why it is used as a model organism for studying: genetics, metabolics, pharmacology, cancer, neuropsychiatric manifestations, ecological toxicology etc. Thus, in this mini-review we are summarizing the aforementioned described aspects, by focusing on the social behavior and how this is influenced by their metabolic, neuropsychiatric and ecotoxicological relevance.
\end{abstract}

KEYWORDS:

Zebrafish, social behavior, metabolism, ecotoxicology. 


\section{INTRODUCTION}

The development and mechanisms underlying the social behavior of vertebrates are not fully understood at present. There are numerous human clinical conditions in which abnormal social behavior is the main symptom, through the main conditions are: alcoholism and fetal alcohol syndrome. To facilitate the understanding of the mechanisms of social behavior and the mechanisms underlying the abnormal social behavior, animal models, such as zebrafish or mice, are often used (Parichy, 2015).

Observations which are made on field of the zebrafish behavior are scarce and anecdotal, because of that, this assessment is analyzed in laboratory. Behavior that has received considerable attention is the formation of free social aggregation, which have been identified and studied in the laboratory field. (Engeszer et al., 2007b; Gerlai, 2014).

Also, experiences with different physical contexts during early development can have dramatic and prolonged effects on behavior, modeling neural systems and other underlying systems in ways that influence later adult behavior (Hensch, 2004; Fu et al., 2011).

\section{THE SOCIAL BEHAVIOR IN ZEBRAFISH}

Teleost fish is the most diverse and biggest taxon existing vertebrate, having until now thousands of species described, having a wide variety of social behaviors. For example, different teleost species of can use a variety of strategies for feeding and mating, parenting behaviors, and social hierarchies. They may differ in their territoriality and degree of aggression, using visual, olfactory and sonorous stimuli. As with other species, the social behavior of fish also depends on their internal state, especially at hormonal levels (Fernald, 2012; Hofmann, 2006).
The social behavior of zebrafish is influenced by the presence or actions of other specific elements (Al-Imari et al., 2008)(8). Some individuals of zebrafish include scaling / schooling, courting, fighting / aggression, and breeding; it can also manifest itself in social recognition, approach / audacity (social investigation) and social preference.

The neuropeptide hormones here modulate the basic physiology that governate social interactions. A multitude of discoveries regarding neuroendocrine mechanisms of social behavior were extrapolated from animal models to humans. During evolution, hypothalamic neuropeptides and hormones which are released kept their structures and also their biological functions, including effects on behavior.

In nature (Engeszer et al., 2007; Spence et al., 2006) and in the laboratory (Gerlai et al., 2000; Miller et al., 2007; Miller et al., 2008), zebrafish aggregate and swim in groups, a behavior called bank. This behavior has an effect is in reducing the risk of predation, thus, the improvement in feeding and breeding was observed. For a detailed understanding of social behavior, internal and external influences leading to the variety of non-human phenotypes are examined. Due to the diversity of pigment patterns among Danio Rerio fish, visual signals may be particularly important in mediating social behaviors in this group. Understanding the development of the pigment model in zebrafish D. Rerio allows for integrative analyzes of how molecular variation leads to morphological variation among individuals and how it influences social interactions.

Social behavior in new contexts can be influenced by recent experiences, but also by the impact of the physical environment on the social behavior of adults, it can persist even 
when moving to new habitats. It was observed that after sheltering in more complex physical environments, zebrafish formed aggregates, which suggests that the main persistent effect is a change in spacing patterns.

\section{CURRENT STUDIES OF SUPERIOR BEHAVIORAL FUNCTIONS ON ZEBRAFISH}

The main complex behaviors were studied zebra fish are: learning and memory, aggression, anxiety, reward dependence, mate choice, social preference and locomotion.

Regarding locomotion (swimming), Gerlai and co-workers (2000), described where and how fast the zebrafish swam on exposure in a new environment, as well as after getting used to the environment. Their purpose is to observe particular swimming patterns, to make analogies with anxiety states, as well as the influence of alcohol (Gerlai et al., 2000)

Reward is one of the areas where adult zebrafish have contributed to behavioral genetics. The reward behavior of animals is an instinctive action to seek resources and to reproduce. This behavior can be altered by the abuse of various drugs, such as: cocaine (Darland et al., 2001), amphetamine (Webb et al., 2009) and opiates (Lau et al., 2006). The reward behavior can be the first step toward addiction. The conditioned place preference test (CPP) is often used to measure reward behavior in zebrafish, which groups a primary clue (for example, a drug) with a secondary stimulus, such as a colored aquarium compartment. The main neurotransmitter associated with reward behavior is dopamine (DA). Brennan and his colleagues observed that there is a robust change in place preference (PP) following nicotine treatment and also ethanol treatment (Killy et al., 2008). A comparison was made on the treated fish brain with those untreated, using microarray analysis, identifying 1362 genes that were altered significantly following drug application, including 153 that responded to both the ethanol and the nicotine.

Learning and memory can be controlled by several circuits of the brain, each of them is distinctly euro-anatomical. Mammal studies include spatial learning (hippocampus), implicit learning (such as simple motor reflexes; cerebellum) and avoidance learning (amygdala). Currently, there are many paradigms for measuring learning and memory in zebrafish. Associative learning can be measured by associating two previously irrelevant stimuli, such as color, reward or aversion (repulsion to something). For example, Suboski and his collaborators associated morphine, which is a neutral stimulus, with the aversion effects of the alarm substance (Suboski et al., 1990). Avoidance learning can be evaluated using a transfer box, fish are able to quickly associate an unconditioned stimulus (for example: slight electric shock) with a conditioned stimulus (for example: light (Xu et al., 2008) or color (Blank et al., 2009). Spatial learning can be measured using either a transfer box (Pather et al., 2009; Williams et al., 2002), or a maze T (Al-Imari et al., 2008). The mechanism being a simple one, the fish must learn to get a reward either by alternating the part of the visited tank or swimming properly through a maze.

Aggression represents a variety of complex behaviors (such as: approaching, undulating body movement, flapping, biting, mouth opening behavior, loading, changing body color, elongation, and surrounding) directed at conspecifics (or other objects) in adults; it can occur in the context of resource protection (eg, women), territorial defense (territorial behavior) and dominance (Jesuthasan et al., 2008). In the laboratory, aggression can be 
(2)

measured by mirror image stimulation (MIS), fish do not recognize their own image, so they become aggressive as if an intruder was present (Gerlai et al., 2000; Rowland et al., 1999). This method avoids damaging the fish and provides immediate feedback on the activity of the subjects (Marks et al., 2005), thus the MIS protocol is simple to establish and execute. Gerlai and his collaborators (2000), observed that zebrafish exhibit agonistic characteristic positions, including erection of the dorsal fins, tail, pectoral and anal coupled to bite, slamming of the tail and short quick swimming strokes against the mirror. Another method of measuring the behavior is presented by Marks and his collaborators (2005), who used the recording interactions of two free-swimming fish. Also, a positive correlation between aggression and boldness has been reported (Moretz et al., 2007), aggression being a very plastic behavior. The number of interactions can be influenced by habitat complexity and growth conditions (Marks et al., 2005; Basquill et al., 1997). In 1999, Miklosi and his collaborators observed a lateralization of the aggression behavior of zebrafish, using mainly the right eye to see the predators. It was observed that the main neurotransmitter 5-hydroxytryptamine (5-HT), which controls the aggressiveness has influence on the animals, those showing a high level tend to be shy, while those with a lower level are more impulsive and more aggressive (Popova et al., 2008). The agonistic behavior of zebrafish can be changed if they are exposed at the pharmacological compounds, including ethanol (Gerl et al., 2000) and $17 \alpha$ etinilestradiol (a synthetic estrogen) (Larson et al., 2006). Arginine vasotocin (AVT), which is a hormone produced by neurosecretory cells from the posterior pituitary gland of the brain is involved in social and sexual behavior, is found in the preoptic magnocellular area and it changes size depending on the state of dominance of the fish. Therefore, the involvement is observed in the preoptic area of zebrafish in controlling the social hierarchy and agonistic behavior that is used to establish it (Larson et al., 2006).

Anxiety is a complex behavior evoked by the environment or by dangerous or potentially dangerous stimuli. This behavior is characterized by reduced exploration and is commonly manifested in thigmotaxis, geotaxis (diving), scototaxis, opercular movements, frost, body color change and zigzag movement (Blaser et al., 2010; Blaser et al., 2012). Anxiolytic drugs generally reduce this anxiety-like behavior, while anxiogenic agents potentiate these responses. Zebrafish anxiety-like behavior frequently overlaps with fear-related behavior (Maximino et al., 2010). Anxiety tests were determined for fish although it is not yet known whether anxiety or fear is measured or whether there are differences between these two states (Blaser et al., 2009). Protocols for measuring anxiety tend to evaluate one of the two variables. The first set of protocols records how adult zebra fish react to unusual environments, such as the time they spend on the edge of a tank. (Peitsaro et al., 2003; Lopez-Patino et al., 2008), at the bottom of a new tank (Levin et al., 2007; Egan et al., 2009) or on the dark side of a light / dark tank (Blank et al., 2009; Serra et al., 1999). The second set of protocols analyzes: freezing, long-term growth of basal locomotor activity (Gerlai et al., 2009; Blaser et al., 2009; Lopez-Patino et al., 2008), and clustering, considered solid measures for measuring anxiety. By comparison with other behaviors, the methods for measuring anxiety have been validated using pharmacological compounds that are used for human patients. Substances that have been shown to be anxiogenic: application of caffeine (Egan et al., 2009; 
Wong et al., 2009), pentylenetetrazol (Wong et al., 2009), the alarm substance (Egan et al., 2009; Speedie et al., 2008) and cocaine withdrawal (Lopez-Patino et al., 2008). In contrast, many anxiolytic substances have been characterized including nicotine (Levin et al., 2006), diazepam (Lopez-Patino et al., 2008; Bencan et al., 2009), fluoxetine hydrochloride and ethanol (Egan et al., 2009). Finally, a link between anxiety and cortisol levels has been demonstrated, which is the main stress hormone of zebrafish (Egan et al., 2009).

\section{THE ALCOHOL EFFECTS}

One of the most widely used drugs in the world is alcohol. The effects of ethanol consumption on rodent neurotransmitters are, in small quantities, stimulated, and through chronic consumption of large quantities they are affected or suppressed (McBride et al., 1990).

Zebra fish is an ideal model for testing drugs, such as alcohol, because its absorption is simple. The alcohol mixed with the water in the reservoir is absorbed through the blood vessels of the gills and into the skin, reaching a balance between the blood alcohol and the alcohol of the reservoir.

In 2000, Gerlai and his collaborators, Suggested that zebrafish as a tool for analyzing the effects of alcohol on adult brain function. The behavioral effects of exposure of zebrafish to alcohol, both acute and chronic, have been investigated (Gerlai, 2003; Gerlai et al. 2006).
In 2000, Gerlai and his collaborators, designed a series of simple, easily quantifiable tests to examine the effects of alcohol administration in different concentrations on locomotion, aggression, tendency to form groups, alarm response, light / dark preference and pigmentation.

Dlugos and Rabin (2003) compared the effects of acute alcohol administration and cornice for three zebrafish strains. The strains differed in terms of the amazing response and the cohesion of the shore, which suggests that there is a genetic basis for both the initial sensitivity and the development of tolerance to alcohol.

Larson and his collaborators (2006) showed that there are clear differences between dominant and subordinate fish in AVT expression, such as aggression, courtship and parental behavior in vertebrates, although the system varies depending on the taxa.

They noticed that in an open space the zebra fish as opposed to rodents, spend the first 5 minutes within a 30-minute interval to explore the area, and the rest as close to the bottom of the area (aquarium). As opposed to rodents, zebrafish have a thigmotactic behavior (movement of an organism in response to contact with a solid body), (Blaser et al., 2010; Buske et al., 2014).

The main effects of alcohol on zebrafish are shown in Table no. I.

Table I. The effects of alcohol

\begin{tabular}{|c|c|c|c|}
\hline Study & Behaviour & $\begin{array}{l}\text { Function/ } \\
\text { Activity }\end{array}$ & Effect \\
\hline Naumann et al., 2010 & Agression & \multirow{4}{*}{ 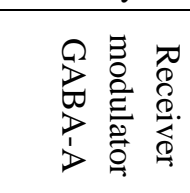 } & Increases aggression \\
\hline Gerlai et al., 2000 & Anti-predatory & & It affects in large doses \\
\hline Egan et al., 2009 & Anxiety & & It reduces anxiety \\
\hline Gerlai et al., 2000 & Group preference & & Reduced to high concentrations \\
\hline
\end{tabular}




\begin{tabular}{|c|c|c|}
\hline Gerlai et al., 2000 & Prefference for light/ dark & Lowered at high concentrations \\
\hline Gerlai et al., 2000 & Locomotion & Reduced at high concentrations \\
\hline Kily et al., 2008 & Reward & Profit \\
\hline
\end{tabular}

*GABA- Acid gamma-aminobutiric

\section{ECOTOXICOLOGICAL RELEVANCE}

Ecotoxicology is a discipline of environment science which requires knowledge in several areas (eg chemistry, ecology, toxicology, climatology, microbiology, engineering, mathematics, public policy and legislation environment), to understand the possible dangers due to chemical substances which are found in pollutants released continuously in aquatic environments around the world. The most common spill cases are heavy metals, pesticides, PAHs (Polycyclic Aromatic Hydrocarb), but often are encountered pharmaceutical products. They present a concern from the toxicity point of view as their interactions with various mixtures emitted by industrial and municipal effluents from various sources of pollution (Blaise 2013).

Zebrafish is widely used to monitor pollute toxicity present in the environment, however, it has several disadvantages, such as: statistical experiments are difficult and low sensitivity of detection. Environmental pollution particularly that of water, is one of the common problems worldwide. Water pollution affects the survival and reproduction of aquatic organisms, and in addition presents affections of human health by bioconcentrate. Zebrafish is susceptible to different pollutants, being considered an ideal model organism for environmental monitoring. The main indicators that were observed are: characteristic changes in morphology, behavior, and physiology and gene expression. The International Organization for Standardization (ISO) first published the zebrafish toxicity test in 1984 (International Organization for Standardization. 1996).

Detection of a specific pollutant may be indirect, on monitoring basis of different parameters. For example, heavy metals could be identified by monitoring the enzyme activity or gene expression of the biomarker (Xu et al., 2008).

The main pollutants which are used in environmental monitoring studies are: heavy metals, endocrine disrupters and organic pollutants, these conditions can be found in Table no.II.

Table II. Applications of zebrafish in environmental monitoring

\begin{tabular}{|l|l|l|l|}
\hline Classes & Contaminants & Study & Diseases \\
\hline Heavy metals & $\begin{array}{l}\text { Cadmium acetate, } \\
\text { lead acetate, } \\
\text { mercury chloride, } \\
\text { zinc chloride }\end{array}$ & Richetti et al., 2011 & It inhibits the activity of enzymes \\
\cline { 2 - 3 } & Mercury chloride & Senger et al., 2010 & Functional impairment and delayed \\
\cline { 2 - 3 } & Metilmercury & Samson et al., 2001 & Reproductive toxicity \\
\cline { 2 - 3 } & Tributyltin & $\begin{array}{l}\text { McAllister and Kime, } \\
2003\end{array}$ & $\begin{array}{l}\text { Susceptibily to infection by listeria } \\
\text { after exposure to copper and zinc }\end{array}$ \\
\cline { 2 - 4 } & Copper and zinc & Rougier al., 1996 \\
\hline
\end{tabular}


Bulletin of Integrative Psychiatry $\bigcirc$ New Series OJune $2020 \bigcirc$ Year XXVI ONo. 2 (85)/77

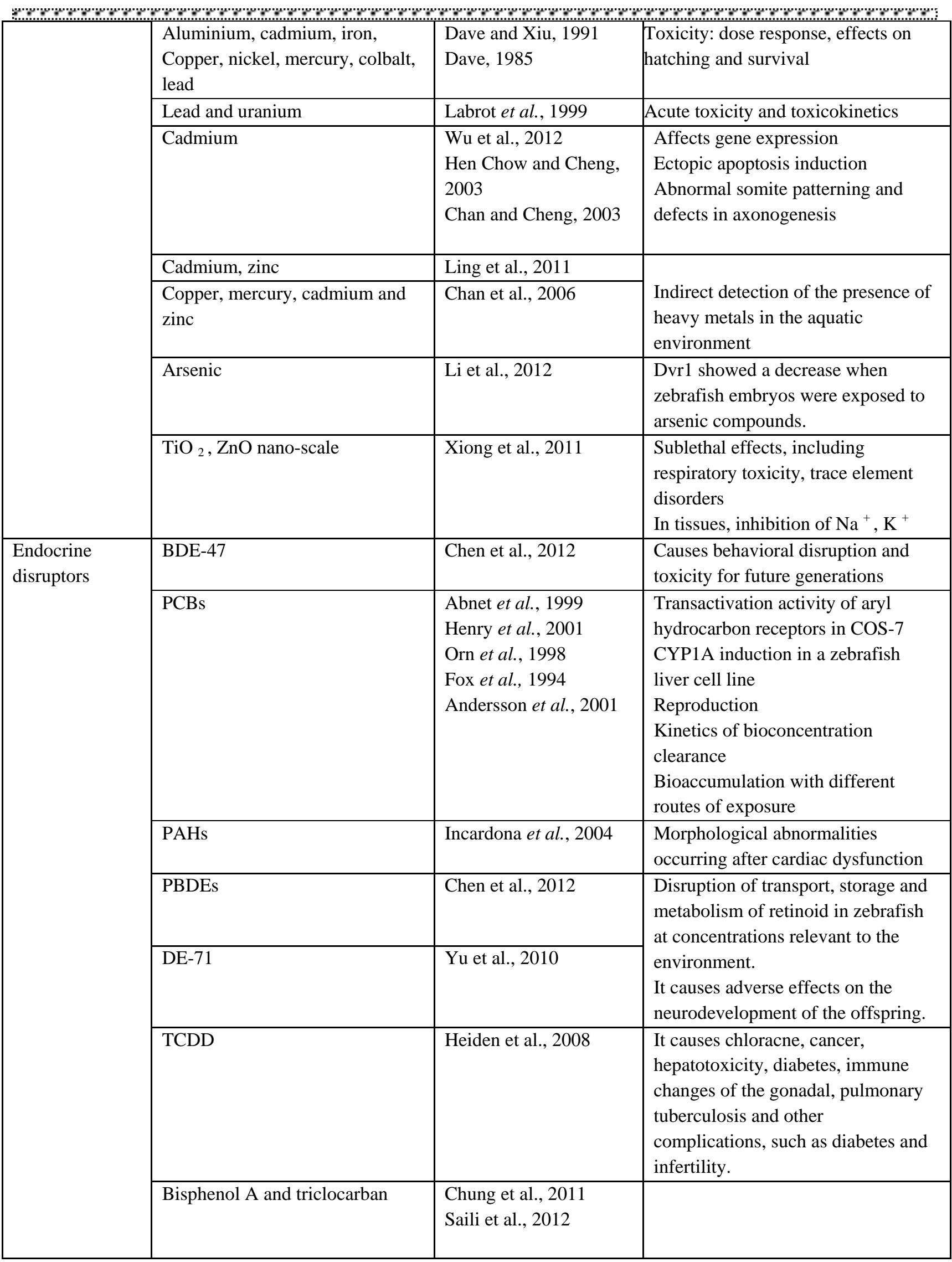




\begin{tabular}{|c|c|c|c|}
\hline & $\begin{array}{l}\text { Bisphenol A, endosulfan, } \\
\text { heptachlor, } \\
\text { methoxychlor, } \\
\text { tetrabromobisphenol A }\end{array}$ & Chow et al. 2012 & $\begin{array}{l}\text { Caused severe malformations of the } \\
\text { otic vesicle. } \\
\text { In small doses, the larva shows } \\
\text { hyperactivity and learning } \\
\text { deficiencies in adult fish. }\end{array}$ \\
\hline \multirow[t]{4}{*}{$\begin{array}{l}\text { Organic } \\
\text { pollutants }\end{array}$} & Chlorpyrifos and nickel chloride & Kienleet al., 2009 & It affects behavior. \\
\hline & chlorpyrifos & $\begin{array}{l}\text { Richendrfer et al., } 2012 \\
\text { Levin et al., } 2003\end{array}$ & $\begin{array}{l}\text { It affects behavior. } \\
\text { Effects on survival, response latency } \\
\text { and spatial discrimination }\end{array}$ \\
\hline & PFNA & Zhang et al., 2012 & $\begin{array}{l}\text { It changes the expression of the } \\
\text { protein gene that binds fatty acids } \\
\text { and affects the level of liver } \\
\text { triglycerides }\end{array}$ \\
\hline & Methyl paration & Huang et al., 2012 & $\begin{array}{l}\text { It affects the activity of some } \\
\text { enzymes }\end{array}$ \\
\hline
\end{tabular}

BDE-47 = brominated diphenyl ether; $\mathrm{PCBs}=$ Polychlorinated biphenyls; $\mathrm{CYP} 1 \mathrm{~A}=$ cytochrome P450 1A; PAHs= Polycyclic aromatic hydrocarbons; PBDEs = polybrominated diphenyl ether, DE$71=$ commercial mixture of PBDEs, TCDD = 2, 3, 7, 8-tetrachloro-p-dioxin, FABP = fatty acid binding proteins, PFNA- = perfluorononanoid aci

\section{CONCLUSIONS}

Zebra fish are an increasingly common model organism used in human disease studies. During their growth, zebrafish are a good model in behavioral neuroscience, and can be used for a broader understanding of behavior make an interest for future research. Also, as a model body for environmental monitoring it has low costs, ease of reproduction and many other advantages, so over time the sensitivity of their monitoring has been continuously improved. In terms of social behavior, it can be influenced by recent experiences, but also by the impact of the physical environment on the social behavior of adults. The relevance in the brain functions and zebrafish behavior has a great interest, as central nervous system (CNS) disorders can be studied and modeled with this species. Alcohol abuse and alcoholism are among the most expensive and devastating diseases, but they are of interest because the mechanism is not known at all, so zebrafish are lately proposed to understand this mechanism.

\section{ACKNOWLEDGE AND DISCLOSURE}

C.A. is currently supported by a PN-III-P1-1.1-TE-2016-1210 grant offered by UEFISCDI.

\section{REFERENCES}

1. Parichy DM, 2005, Chapter 20 Variation and developmental biology: prospects for the future, In: Halgrimsson B, Hall BK, editors, Variation: a hierarchical examination of a central concept in biology, New York, NY: Academic Press, p. 475-498.

2. Engeszer RE, Patterson LB, Rao AA, Parichy DM, 2007b, Zebrafish in the wild: a review of natural history and new notes from the field, Zebrafish 4:21-40.

3. Gerlai R, 2014, Social behavior of zebrafish: from synthetic images to biological mechanisms of shoaling, Journal of Neuroscience Methods 234:59-65.

4. Hensch TK. Critical period regulation, Annu Rev Neurosci. 2004;27(1):549-79.

5. Fu M, Zuo Y. Experience-dependent structural plasticity in the cortex, Trends Neurosci. 2011; 34 (4):177-87.

6. Blaise, C., Gagné, F., 2013, Aquatic ecotoxicology: what has been accomplished and what lies ahead? An Eastern Canada historical perspective, Journal of Xenobiotics, 3. 10.4081/xeno.2013.e8. 


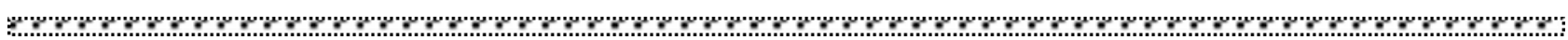

7. Xu C, Wang J, Liu W, Daniel Sheng G, Tu Y, Ma Y, 2008, Separation and aquatic toxicity of enantiomers of the pyrethroid insecticide lambdacyhalothrin, Environ Toxicol Chem, 27:174-181.

8. Richetti SK, Rosemberg DB, Ventura-Lima J, Monserrat JM, Bogo MR, Bonan CD, 2011, Acetylcholinesterase activity and antioxidant capacity of zebrafish brain is altered by heavy metal exposure, Neurotoxicology, 32:116-122.

9. Senger MR, Rosemberg DB, Seibt KJ, Dias RD, Bogo MR, Bonan CD, 2010, Influence of mercury chloride on adenosine deaminase activity and gene expression in zebrafish (Danio rerio) brain, Neurotoxicology, 31:291-296.

10. Samson, J. C., Goodridge, R., Olobatuyi, F., and Weis, J. S., 2001, Delayed effects of embryonic exposure of zebrafish (Danio rerio) to methylmercury (MeHg), Aquat. Toxicol.51, 369-376.

11. McAllister, B. G., and Kime, D. E. (2003), Early life exposure to environmental levels of the aromatase inhibitor tributyltin causes masculinization and irreversible sperm damage in zebrafish (Danio rerio), Aquat. Toxicol.65, 309316.

12. Rougier, F., Menudier, A., Bosgiraud, C., and Nicolas, J. A., 1996, Copper and zinc exposure of zebrafish, Brachydanio rerio (Hamilton-Buchaman): Effects in experimental Listeria infection, Ecotoxicol. Environ. Saf.34, 134-140

13. Dave, G., and Xiu, R. Q, 1991, Toxicity of mercury, copper, nickel, lead, and cobalt to embryos and larvae of zebrafish, Brachydanio rerio, Arch. Environ. Contam. Toxicol. 21, 126-134.

14. Dave, G., 1985, The influence of $\mathrm{pH}$ on the toxicity of aluminum, cadmium, and iron to eggs and larvae of the zebrafish, Brachydanio rerio, Ecotoxicol. Environ. Saf.10, 253-267.

15. Labrot, F., Narbonne, J. F., Ville, P., Saint Denis, M., and Ribera, D. (1999), Acute toxicity, toxicokinetics, and tissue target of lead and uranium in the clam Corbicula fluminea and the worm Eisenia fetida: Comparison with the fish Brachydanio rerio, Arch. Environ. Contam. Toxicol. 36, 167-178.

16. Wu SM, Tsai PR, Yan CJ, 2012, Maternal cadmium exposure induces $\mathrm{mt} 2$ and smtB mRNA expression in zebrafish (Danio rerio) femalesand their offspring. Comp Biochem Physiol C Toxicol Pharmacol, 156:1-6.

17. Hen Chow, E. S., and Cheng, S. H., 2003, Cadmium affects muscle type development and axon growth in zebrafish embryonic somitogenesis, Toxicol. Sci. 73, 149-159.

18. Chan, P. K., and Cheng, S. H., 2003, Cadmium-induced ectopic apoptosis in zebrafish embryos, Arch. Toxicol. 77, 69-79.

19. Ling X, Zhang Y, Lu Y, Huang H, 2011, Superoxide dismutase, catalase and acetylcholinesterase: Biomarkers for the joint effects of cadmium, zinc and methyl parathion contamination in water, Environ Technol, 32:1463-1470.

20. Chan KM, Ku LL, Chan PC, Cheuk WK, 2006, Metallothionein gene expression in zebrafish embryo-larvae and ZFL cell-line exposed to heavy metal ions, Mar Environ Res 62(Suppl):S83-87

21. Li X, Ma Y, Li D, Gao X, Li P, Bai N, Luo M, Tan X, Lu C, Ma X, 2012, Arsenic impairs embryo development via down-regulating Dvr1 expression in zebrafish. Toxicol Lett, 212:161-168.

22. Xiong D, Fang T, Yu L, Sima X, Zhu W, 2011, Effects of nano-scale $\mathrm{TiO}_{2}, \mathrm{ZnO}$ and their bulk counterparts on zebrafish: Acute toxicity, oxidative stress and oxidative damage, Sci Total Environ, 409:1444-1452.

23. Chen X, Huang C, Wang X, Chen J, Bai C, Chen Y, Dong Q, Yang D, 2012, BDE-47 disrupts axonal growth and motor behavior in developing zebrafish, Aquat Toxicol 120-121:35-44.

24. Abnet, C. C., Tanguay, R. L., Heideman, W., Peterson, R. E., 1999, Transactivation activity of human, zebrafish, and rainbow trout aryl hydrocarbon receptors expressed in COS-7 cells: Greater insight into species differences in toxic potency of polychlorinated dibenzo-p-dioxin, dibenzofuran, and biphenyl congeners, Toxicol. Appl. Pharmacol. 159, 41-51.

25. Henry, T. R., Nesbit, D. J., Heideman, W., and Peterson, R. E., 2001, Relative potencies of polychlorinated dibenzo-p-dioxin, dibenzofuran, and biphenyl congeners to induce cytochrome P4501A mRNA in a zebrafish liver cell line, Environ. Toxicol. Chem. 20, 1053-1058.

26. Orn, S., Andersson, P. L., Forlin, L., Tysklind, M., and Norrgren, L., 1998, The impact on reproduction of an orally administered mixture of selected PCBs in zebrafish (Danio rerio), Arch. Environ. Contam. Toxicol. 35, 52-57.

27. Fox, K., Zauke, G. P., and Butte, W., 1994, Kinetics of bioconcentration and clearance of 28 polychlorinated biphenyl congeners in zebrafish (Brachydanio rerio), Ecotoxicol. Environ. Saf. 28, 99-109.

28. Andersson, P. L., Berg, A. H., Bjerselius, R., Norrgren, L., Olsen, H., Olsson, P. E., Orn, S., and Tysklind, M., 2001, Bioaccumulation of selected PCBs in zebrafish, three-spined stickleback, and arctic char after three different routes of exposure, Arch. Environ. Contam. Toxicol. 40, 519-530. 
29. Incardona, J. P., Collier, T. K., and Scholz, N. L., 2004, Defects in cardiac function precede morphological abnormalities in fish embryos exposed to polycyclic aromatic hydrocarbons, Toxicol. Appl. Pharmacol. 196, $191-205$.

30. Chen L, Hu C, Huang C, Wang Q, Wang X, Yang L, Zhou B, 2012, Alterations in retinoid status after long-term exposure to PBDEs in zebrafish (Danio rerio), Aquat Toxicol 120-121:11-18.

31. Yu L, Deng J, Shi X, Liu C, Yu K, Zhou B, 2010, Exposure to DE-71 alters thyroid hormone levels and gene transcription in the hypothalamicpituitary-thyroid axis of zebrafish larvae, Aquat Toxicol 97:226-233.

32. Heiden TC, Struble CA, Rise ML, Hessner MJ, Hutz RJ, Carvan MJ $3^{\text {rd }}$, 2008, Molecular targets of 2,3,7,8tetrachlorodibenzo-p-dioxin (TCDD) within the zebrafish ovary: Insights into TCDD-induced endocrine disruption and reproductive toxicity, Reprod Toxicol 25:47-57,

33. Chung E, Genco MC, Megrelis L, Ruderman JV, 2011, Effects of bisphenol A and triclocarban on brain-specific expression of aromatase in early zebrafish embryos, Proc Natl Acad Sci U S A, 108:17732-17737.

34. Chow WS, Chan WK, Chan KM, 2012, Toxicity assessment and vitellogenin expression in zebrafish (Danio rerio) embryos and larvae acutely exposed to bisphenol A, endosulfan, heptachlor, methoxychlor and tetrabromobisphenol A, J Appl Toxicol.

35. Kienle C, Kohler HR, Gerhardt A, 2009, Behavioural and developmental toxicity of chlorpyrifos and nickel chloride to zebrafish (Danio rerio) embryos and larvae, Ecotoxicol Environ Saf 72:1740-1747.

36. Richendrfer H, Pelkowski SD, Colwill RM, Creton R, 2012, Developmental sub-chronic exposure to chlorpyrifos reduces anxietyrelated behavior in zebrafish larvae, Neurotoxicol Teratol 34:458-465.

37. Levin, E. D., Chrysanthis, E., Yacisin, K., and Linney, E., 2003, Chlorpyrifos exposure of developing zebrafish: Effects on survival and long-term effects on response latency and spatial discrimination. Neurotoxicol. Teratol. 25, 5157.

38. Zhang W, Zhang Y, Zhang H, Wang J, Cui R, Dai J, 2012, Sex differences in transcriptional expression of FABPs in zebrafish liver after chronic perfluorononanoic acid exposure, Environ Sci Technol, 46:5175-5182.

39. Huang Q, Huang HQ, 2012, Alterations of protein profile in zebrafish liver cells exposed to methyl parathion: A membrane proteomics approach, Chemosphere 87:68-76.

40. Fernald, 2012, Social Control of the Brain, Annual Review of Neuroscience 35, 133-151.

41. Hofmann, 2006, The emotional consequences of social pragmatism: The psychophysiological consequences of self-monitoring, Biological Psychology, 73, 169-173

42. Engeszer RE, Patterson LB, Rao AA, Parichy DM, 2007, Zebrafish in the wild: a review of natural history and new notes from the field, Zebrafish, 4:21-40.

43. Spence R, Fatema MK, Reichard M, Huq K. A., Wahab M. A., Ahmed Z. F., et al., 2006, The distribution and habitat preferences of the zebrafish in Bangladesh, J Fish Biol, 69:1435-1448.

44. Gerlai R., Lahav M., Guo S., Rosenthal A., 2000, Drinks like a fish: zebra fish (Danio rerio) as a behavior genetic model to study alcohol effects, Pharmacol Biochem Behav67: 773-782.

45. Miller N., Gerlai R., 2007, Quantification of shoaling 80ehavior in zebrafish (Danio rerio), Behav Brain Res, 184:157- 166.

46. Miller N., Gerlai R., 2008, Oscillations in shoal cohesion in zebrafish (Danio rerio), Behav Brain Res, 193:148151.

47. Miller N., Gerlai R., 2011, Shoaling in zebrafish: what we don’t know, Rev Neurosci., 22:17-25.

48. Saverino C., Gerlai R., 2008, The social zebrafish: behavioral responses to conspecific, heterospecific, and computer animated fish, Behav Brain Res, 191:77-87.

49. Darland T., Dowling J. E., 2001, Behavioral screening for cocaine sensitivity in mutagenized zebrafish, Proc Natl Acad Sci. 98:11691-11696.

50. Webb K. J., Norton W. H., Trumbach D., Meijer A. H., Ninkovic J., Topp S., Heck D., Marr C., Wurst W., Theis F. J., 2009, Zebrafish reward mutants reveal novel transcripts mediating the behavioral effects of amphetamine, Genome Biol, 10:R81.

51. Lau B., Bretaud S., Huang Y., Lin E., Guo S., 2006, Dissociation of food and opiate preference by a genetic mutation in zebrafish, Genes Brain Behav., 5:497-505

52. Kily LJ, Cowe YC, Hussain O, Patel S, McElwaine S, Cotter FE, Brennan CH: Gene expression changes in a zebrafish model of drug dependency suggest conservation of neuro-adaptation pathways, J Exp Biol 2008, 211:16231634. 
r.

53. Suboski MD, Bain S, Carty AE, McQuoid LM, Seelen MI, Seifert M: Alarm reaction in acquisition and social transmission of simulated-predator recognition by zebra Danio fish (Brachydanio rerio), J Comp Psych 1990, 104:101112

54. Xu X, Scott-Scheiern T, Kempker L, Simons K, 2007, Active avoidance conditioning in zebrafish (Danio rerio), Neurobiol Learn Mem, 87:72-77

55. Blank M, Guerim LD, Cordeiro RF, Vianna MR, 2009, A one-trial inhibitory avoidance task to zebrafish: rapid acquisition of an NMDA-dependent long-term memory, Neurobiol Learn Mem., 92:529-534.

56. Al-Imari L, Gerlai R, 2008, Sight of conspecifics as reward in associative learning in zebrafish (Danio rerio), Behav Brain Res., 189:216-219.

57. Jesuthasan S, 2012, Fear, anxiety and control in the zebrafish, Dev Neurobiol, 72:395-403,

58. Pather S, Gerlai R, 2009, Shuttle box learning in zebrafish (Danio rerio), Behav Brain Res., 196:323-327.

59. Williams FE, White D, Messer WS, 2002, A simple spatial alternation task for assessing memory function in zebrafish, Behav Processes, 58:125-132.

60. Marks C, West TN, Bagatto B, Moore FB-G, 2005, Developmental environment alters conditional aggression in zebrafish, Copeia.

61. Rowland WJ, 1999, Studying visual cues in fish 81ehavior: a review of ethological techniques, Environmental Biology of Fishes, 56:285-305.

62. Moretz JA, Martins EP, Robison BD, 2007, Behavioural syndromes and the evolution of correlated behavior in zebrafish, Behavioral Ecology, 1-7.

63. Basquill SP, Grant JWA, 1997, An increase in habit complexity reduces aggression and monopolization of food by zebra fish (Danio rerio), Can J Zool, 76:770-772.

64. Miklosi A, Andrew RJ, 1999, Right eye use associated with decision to bite in zebrafish, Behav Brain Res., 105:199-205.

65. Popova NK, 2008, From gene to aggressive behavior: the role of brain serotonin, Neurosci Behav. Physiol., 38:471-475.

66. Larson ET, O’Malley DM, Melloni RH Jr, 2006, Aggression and vasotocin are associated with dominantsubordinate relationships in zebrafish, Behav Brain Res., 167:94-102.

67. Blaser RE, Chadwick L, McGinnis GC, 2010, Behavioral measures of anxiety in zebrafish (Danio rerio), Behav Brain Res, 208:56-62.

68. Blaser RE, Rosemberg DB, 2012, Measures of anxiety in zebrafish (Danio rerio): Dissociation of black/white preference and novel tank test, PloS ONE, 7:e36931

69. Maximino C, de Brito TM, da Silva Batista AW, Herculano AM, Morato S, Gouveia A, Jr. 2010, Measuring anxiety in zebrafish: A critical review, Behav Brain Res, 214:157-171.

70. Blaser RE, Chadwick L, McGinnis GC, 2009, Behavioral measures of anxiety in zebrafish (Danio rerio), Behav Brain Res, 208:56-62.

71. Peitsaro N, Kaslin J, Anichtchik OV, Panula P, 2003, Modulation of the histaminergic system and 81ehavior by alpha-fluoromethylhistidine in zebrafish. J Neurochem, 86:432-441.

72. Lopez-Patino MA, Yu L, Cabral H, Zhdanova IV, 2008, Anxiogenic effects of cocaine withdrawal in zebrafish. Physiol Behav., 93:160-171.

73. Levin ED, Bencan Z, Cerutti DT, 2007, Anxiolytic effects of nicotine in zebrafish, Physiol Behav, 90:54-58.

74. Egan RJ, Bergner CL, Hart PC, Cachat JM, Canavello PR, Elegante MF, Elkhayat SI, Bartels BK, Tien AK, Tien $\mathrm{DH}$, et al, 2009, Understanding behavioral and physiological phenotypes of stress and anxiety in zebrafish, Behav Brain Res, 205:38-44.

75. Serra EL, Medalha CC, Mattioli R, 1999, Natural preference of zebrafish (Danio rerio) for a dark environment, Braz J Med Biol Res, 32:1551-1553.

76. Blank M, Guerim LD, Cordeiro RF, Vianna MR, 2009, A one-trial inhibitory avoidance task to zebrafish: rapid acquisition of an NMDA-dependent long-term memory, Neurobiol Learn Mem, 92:529-534.

77. Wong K, Elegante M, Bartels B, Elkhayat S, Tien D, Roy S, Goodspeed J, Suciu C, Tan J, Grimes C, et al, 2009, Analyzing habituation responses to novelty in zebrafish (Danio rerio), Behav Brain Res, 208:450-457.

78. Speedie N, Gerlai R, 2008, Alarm substance induced behavioral responses in zebrafish (Danio rerio), Behav Brain Res, 188:168-177. 
79. Bencan Z, Sledge D, Levin ED, 2009, Buspirone, chlordiazepoxide and diazepam effects in a zebrafish model of anxiety, Pharmacol Biochem Behav, 94:75-80.

80. McBride WJ, Murphy JM, Lumeng L, Li TK, 1990, Serotonin, dopamine and GABA involvement in alcohol drinking of selectively bred rats, Alcohol, 7:199-205.

81. Dlugos CA, Rabin RA, 2003, Ethanol effects on three strains of zebrafish: model system for genetic investigations, Pharmacol Biochem Behav, 74:471-480.

82. Naumann EA, Kampff AR, Prober DA, Schier AF, Engert F: Monitoring neural activity with bioluminescence during natural behavior, Nat Neurosci 13:513-520.

83. Buske, C., Gerlai, R., 2010, Shoaling develops with age in Zebrafish (Danio rerio). Prog .Neuropsychopharmacol Biol. Psychiatry, doi:10.1016/j.pnpbp.2010.09.003.

\section{Correspondence:}

Daniel Timofte,

MD, PhD, professor, “Grigore T.Popa” University of Medicine and Pharmacy, 16, Universitatii

Street, 700115, Iasi, Romania, dantimofte@yahoo.com

Submission:22 feb 2020

Acceptanec: 17 apr 2020 